\title{
Pengaruh layanan perbankan digital pada kepuasan nasabah perbankan
}

\author{
Lilis Susilawaty* \\ Universitas Bunda Mulia, Jl. Lodan Raya No. 2 Jakarta Utara, 11430, Indonesia \\ lsusilawaty@bundamulia.ac.id \\ Nicola Nicola \\ Universitas Bunda Mulia, Jl. Lodan Raya No. 2 Jakarta Utara, 11430, Indonesia \\ nieco.bong@gmail.com \\ *Penulis Korespondensi
}

Submitted: Apr 24, 2020; Reviewed: Apr 30, 2020; Accepted: May 12, 2020

\begin{abstract}
This study aims to determine whether digital banking services affect banking customer satisfaction. In accordance with previous research contained there are six measurements of digital banking services that affect of banking customer satisfaction, namely comfort, functional quality, employee customer involvement, quality of digital banking services, brand/ trust, and digital banking innovation (Mbama \& Ezepue, 2018). The data analysis technique used is quantitative verification analysis. The data used are primary data where the questionnaire was distributed to respondents using digital banking services of PT Bank Central Asia, Tbk. (Bank BCA). For the hypothesis, multiple regression analysis is tested. Before testing the data instrument testing and classical assumption tests are performed. In total 136 respondents, the results of this study indicate that comfort, functional quality, quality of digital banking services, brand/ trust, employee customer involvement, and digital banking innovation significantly influence customer satisfaction performance at Bank BCA. But partially, showing comfort, the quality of digital banking services, and brand/ trust does not affect the performance of banking customer satisfaction. Whereas functional quality, employee customer involvement, and digital banking innovation influence the performance of banking customer satisfaction.
\end{abstract}

Keywords: banking customer satisfaction performance; digital banking innovation; digital banking service quality

Abstrak: Penelitian ini bertujuan untuk mengetahui apakah layanan digital perbankan berpengaruh terhadap kepuasan nasabah perbankan. Sesuai dengan penelitian terdahulu terdapat enam pengukuran layanan digital perbankan yang berpengaruh terhadap kepuasan nasabah perbankan yaitu kenyamanan, kualitas fungsional, employee customer engagement, digital banking service quality, merek/kepercayaan, dan inovasi perbankan digital (Mbama \& Ezepue, 2018). Teknik analisis data yang digunakan adalah analisis verifikatif kuantitatif. Data yang digunakan adalah data primer yang mana dibagikannya kuesioner kepada responden yang menggunakan layanan digital perbankan PT Bank Central Asia, Tbk. (Bank BCA). Untuk hipotesis dilakukan pengujian analisis regresi berganda. Sebelum pengujian tersebut dilakukannya pengujian instrumen data dan uji asumsi klasik. Total keseluruhan 136 orang responden, hasil penelitian ini menunjukkan bahwa kenyamanan, kualitas fungsional, digital banking service quality, merek/ kepercayaan, employee customer engagement, dan inovasi perbankan digital berpengaruh signifikan terhadap kinerja kepuasan nasabah Bank BCA. Namun secara parsial, menunjukkan kenyamanan, digital banking service quality, dan merek 
/kepercayaan tidak berpengaruh terhadap kinerja kepuasan nasabah perbankan. Sedangkan kualitas fungsional, employee customer engagement, dan inovasi perbaankan digital berpengaruh terhadap kinerja kepuasan nasabah perbankan.

Kata kunci: inovasi perbankan digital; kinerja kepuasan nasabah perbankan; kualitas layanan digital perbankan

\section{PENDAHULUAN}

Keberhasilan pembangunan pertumbuhan ekonomi ditandai dengan sistem keuangan yang stabil dan dapat memberikan manfaat bagi semua lapisan masyarakat. Institusi keuangan sangatlah penting karena menjadi pendorong untuk pertumbuhan ekonomi, pemerataan pendapatan, pemberantasan kemiskinan, dan serta pencapaian stabilitas keuangan. Industri keuangan yang semakin berkembang pesat tidak serta merta disertai dengan akses ke keuangan yang memadai. Padahal akses jasa layanan keuangan merupakan syarat penting keterlibatan masyarakat luas dalam pembangunan sistem perekonomian.

Bank adalah suatu lembaga kepercayaan masyarakat yang digunakan untuk menyimpan uang dan memercayakan bank dalam mengelola keuangannya. Bank secara operasional dibedakan menjadi dua antara lain bank konvensional dan bank syariah. Bank konvensional adalah suatu bank yang melaksanakan kegiatan usahanya secara konvensional dan berdasarkan prosedur atau ketentuan yang telah ditetapkan. Seperti yang diketahui perbankan merupakan salah satu sektor yang dapat membantu meningkatkan perekonomian Indonesia. Perbankan meningkatkan pertumbuhan Indonesia dengan sumber pendapatan yang diperoleh bank itu sendiri. Sumber pendapatan bank dapat berupa margin dari bunga perbankan, fee based income, dan lain-lain.

Kondisi perekonomian yang saat ini tidak stabil dan berisiko tentunya akan memberikan dampak yang besar bagi perbankan. Apalagi semakin berkembangnya teknologi inilah yang memicu adanya perubahan bisnis akibat inovasi teknologi yang semakin berkembang pesat. Apabila di masa lalu inovasi teknologi hanya berpusat pada internal perbankan, akan tetapi saat ini terjadi perubahan drastis di mana inovasi teknologi sekarang telah merambah ke sisi nasabah atau konsumen. Pergeseran inilah yang memunculkan perusahaan keuangan yang berbasis teknologi atau yang lebih dikenal dengan istilah FinTech (Financial Tehnology). FinTech ini sudah menjamur di seluruh dunia termasuk Indonesia. Namun terdapat sebuah penelitian menyatakan bahwa mulanya banyak yang berpersepsi FinTech dapat mengganti posisi bank di dunia perekonomian, akan tetapi pada saat ini dengan kehadiran FinTech belum dapat menggantikan posisi bank, dan bahkan berjalan atau beroperasi berdampingan sehingga kemajuan ekonomi dapat dilakukan bersama (Kholis, 2018).

Untuk mengantisipasi dari perkembangan FinTech, pihak perbankan dituntut mengubah strategi bisnisnya. Tantangan yang dihadapi perbankan saat ini adalah pengalaman yang buruk yang diakibatkan keengganan nasabah. Hal ini juga berdampak pada perbankan di mana kantor cabangnya mengalami penutupan secara besar-besaran. Sukmana (2019) mengemukakan bahwa industri perbankan sedang mengalami fenomena penutupan kantor cabang akibat perkembangan digitalisasi layanan perbankan. Sebagaimana untuk mencukupi kebutuhan nasabahnya guna meningkatkan pertumbuhan dan keuangan perbankan, maka pelayanan bank dimaksimalkan melalui digital perbankan yang di mana generasi millenial saat ini dapat menjadi preferensi utama pada pemakai mobile banking, internet banking, ATM, sms banking, dan lain-lain.

Salah satu bank yang telah bertransformasi ke arah digitalisasi adalah PT Bank Central Asia, Tbk. (Bank BCA). Tren digitalisasi di dunia perbankan turut diakui Bank BCA, terbukti sebanyak 97 persen transaksi di Bank BCA telah dilakukan secara online. Bank BCA juga telah menyediakan semua fitur oneclick untuk memberikan kemudahan transaksi bagi para nasabahnya. Transaksi melalui ATM diketahui dulu sebanyak 70 persen, kini angka tersebut turun menjadi 17 persen dibandingkan dari total transaksi. Sedangkan pengguna mobile banking diketahui naik dari 4.2 persen menjadi 46.5 persen dan pengguna internet banking turut melambung dari 7.6 persen menjadi 28.5 persen (Hastuti, 2019). Seperti yang kita ketahui bahwa dulunya banyak perbankan yang bersaing membuka kantor cabang sehingga dapat selangkah lebih dekat dengan nasabah, saat ini perbankan cukup memberikan pelayanan digital 
demi kemudahan dan kecepatan bertransaksi tanpa harus datang ke cabang (Koran SINDO, 2019). Peningkatan layanan digital perbankan ini disebabkan Bank BCA merespon perkembangan era digital banking dengan memerbanyak produk, layanan, maupun aplikasi berbasis internet demi menjangkau besarnya potensi pasar generasi millennial. Diketahui para generasi millennial menyukai mobilitas tinggi sehingga kemudahan dan kecepatan dalam bertransaksi menjadi prioritas utama generasi ini. Sejalan dengan perkembangan generasi ini, tentunya kepuasan nasabah menjadi prioritas utama untuk dapat memertahankan nasabah agar tidak pindah ke bank lainnya. Untuk itu bank dituntut untuk mampu berinovasi memberikan layanan terbaik bagi para nasabahnya.

Berdasarkan uraian latar belakang, penulis tertarik untuk melakukan penelitian lebih lanjut, mengenai apakah layanan digital perbankan memiliki pengaruh pada kepuasan nasabah perbankan khususnya nasabah Bank BCA. Pengukuran untuk melihat tingkat kepuasan nasabah akan layanan digital perbankan yang diberikan dapat berupa kenyamanan, perceived risk, perceived usability, perceived value, employee customer engagement, digital banking service quality, kualitas fungsional, merek/ kepercayaan, inovasi perbankan digital, dan lain-lain. Pengukuran layanan tersebut juga pernah dilakukan oleh beberapa peneliti, salah satunya Mbama \& Ezepue (2018) yang menyatakan bahwa terdapat pengaruh yang signifikan antara kenyamanan, perceived risk, perceived usability, perceived value, employee customer engagement, digital banking service quality, kualitas fungsional, merek/ kepercayaan, dan inovasi perbankan digital terhadap kinerja kepuasan nasabah perbankan. Dalam penelitian ini, pengukuran layanan digital perbankan menggunakan pengukuran dalam penelitian Vebiana (2018) yaitu kenyamanan, kualitas fungsional, employee customer engagement, digital banking service quality, merek/ kepercayaan, dan inovasi perbankan digital. Yang mana dasar pengukuran variabel ini merupakan aspek penentu layanan digital dalam industri perbankan.

\section{METODE}

Teknik analisis yang digunakan adalah analisis verikatif kuantitatif. Data yang digunakan adalah data primer yang mana dibagikan kuesioner kepada responden. Dalam penelitian ini respondennya adalah seluruh nasabah yang ada di Indonesia khususnya nasabah yang menggunakan layanan digital perbankan Bank BCA. Adapun cara yang dilakukan untuk menghitung sampel menggunakan rumus Tabachnick \& Fidel (2013) yaitu:

$\mathrm{N} \geq 50+8 \mathrm{~m}$

Keterangan:

$\mathrm{N}$ : ukuran sampel

m: jumlah variabel

$\mathrm{N} \geq 50+8 \mathrm{~m}$

$\mathrm{N} \geq 50+8.7$

$\mathrm{N} \geq 106$

Jadi, ukuran sampel minimal dalam penelitian ini adalah 106 orang responden. Teknik sampling yang digunakan adalah teknik sampling kuota. Untuk hipotesis dilakukan pengujian analisis regresi berganda. Sebelum pengujian tersebut dilakukannya pengujian instrumen data dan uji asumsi klasik.

\section{HASIL DAN PEMBAHASAN}

\subsection{Data responden}

Data yang digunakan dalam penelitian ini adalah data primer yang mana penulis mengumpulkan data tersebut dengan menyebarkan kuesioner kepada responden. Kuesioner dalam penelitian ini disebar menggunakan google form. Jumlah kuesioner yang telah disebar keseluruhan terdapat 136 orang responden, yang mana sejumlah responden tersebut merupakan nasabah dari Bank BCA. 
Tabel 1. Data responden

\begin{tabular}{|c|c|c|}
\hline Karakteristik responden & Kategori & Persentase \\
\hline \multirow[t]{5}{*}{$\overline{\text { Usia }}$} & 20 s.d 24 Tahun & $91.9 \%$ \\
\hline & 25 s.d 29 Tahun & $5.9 \%$ \\
\hline & 30 s.d 34 Tahun & $1.5 \%$ \\
\hline & 35 s.d 39 Tahun & $0 \%$ \\
\hline & $>40$ Tahun & $0.7 \%$ \\
\hline \multirow[t]{2}{*}{ Jenis kelamin } & Laki-laki & $34.6 \%$ \\
\hline & Perempuan & $65.4 \%$ \\
\hline \multirow[t]{6}{*}{ Tingkat pendidikan } & $\mathrm{SD}$ & $0 \%$ \\
\hline & SMP & $0.7 \%$ \\
\hline & SMA & $68.4 \%$ \\
\hline & Diploma & $0 \%$ \\
\hline & Sarjana (S1) & $22.1 \%$ \\
\hline & Pascasarjana (S2) & $8.8 \%$ \\
\hline \multirow[t]{4}{*}{ Lama menjadi nasabah Bank BCA } & $<1$ Tahun & $7.4 \%$ \\
\hline & 1 s.d 2 Tahun & $34.6 \%$ \\
\hline & 3 s.d 4 Tahun & $26.5 \%$ \\
\hline & $>4$ tahun & $31.6 \%$ \\
\hline \multirow[t]{9}{*}{ Pekerjaan } & PNS & $0 \%$ \\
\hline & Wiraswasta & $2.2 \%$ \\
\hline & Pegawai Swasta & $18.4 \%$ \\
\hline & TNI/ POLRI & $0 \%$ \\
\hline & Pelajar/ Mahasiswa & $76.5 \%$ \\
\hline & Guru & $0.7 \%$ \\
\hline & Karyawan & $0.7 \%$ \\
\hline & Admin & $0.7 \%$ \\
\hline & Dosen & $0.7 \%$ \\
\hline \multirow{3}{*}{$\begin{array}{l}\text { Fasilitas digital perbankan } \\
\text { (boleh lebih dari 1) }\end{array}$} & Mobile Banking & $86.8 \%$ \\
\hline & Internet Banking & $39.7 \%$ \\
\hline & ATM & $88.2 \%$ \\
\hline \multirow{7}{*}{$\begin{array}{l}\text { Fasilitas digunakan untuk } \\
\text { (boleh lebih dari 1) }\end{array}$} & Menabung & $63.2 \%$ \\
\hline & Cek saldo & $91.2 \%$ \\
\hline & Pembayaran & $90.4 \%$ \\
\hline & Penutupan rekening melalui ATM & $3.7 \%$ \\
\hline & Transfer & $97.1 \%$ \\
\hline & Pembukaan rekening & $11.8 \%$ \\
\hline & Pengisian $e$-money & $33.1 \%$ \\
\hline
\end{tabular}

Sumber: Hasil pengolahan SPSS (2020) 


\subsection{Hasil uji validitas dan reliabilitas}

Uji validitas dilakukan dengan menghitung korelasi antar skor total. Untuk kriteria pengujian dalam penelitian ini diperoleh nilai korelasi antara skor item dengan skor total yang kemudian akan dibandingkan dengan nilai Tabel-r. Tabel-r dalam penelitian menggunakan tabel signifikansi 5\% atau 0.05 dengan uji dua (2) sisi dan jumlah keseluruhan responden adalah 136 orang responden sehingga tabel-r yang diperoleh sebesar 0.176. Tabel 2 merupakan hasil pengujian validitas mengenai butir instrumen kenyamanan yang diberi kode $\mathrm{K}$, kualitas fungsional yang diberi kode $\mathrm{KF}$, digital banking service quality yang diberi kode SQ, merek atau kepercayaan yang diberi kode $\mathrm{M}$, employee customer engagement yang diberi kode EC, inovasi perbankan digital yang diberi kode IP, dan kepuasan nasabah yang diberi kode KN. Untuk memermudah pembaca mengerti maksud Tabel 2 ini penulis memberi kode untuk setiap instrumen dari variabel penelitian ini.

Tabel 2. Hasil uji validitas

\begin{tabular}{lll}
\hline Variabel/ indikator & Nilai R hitung & Status \\
\hline K1 & 0.688 & Valid \\
K2 & 0.717 & Valid \\
K3 & 0.688 & Valid \\
KF1 & 0.814 & Valid \\
KF2 & 0.833 & Valid \\
KF3 & 0.813 & Valid \\
SQ1 & 0.779 & Valid \\
SQ2 & 0.778 & Valid \\
SQ3 & 0.681 & Valid \\
SQ4 & 0.752 & Valid \\
M1 & 0.795 & Valid \\
M2 & 0.869 & Valid \\
M3 & 0.832 & Valid \\
EC1 & 0.834 & Valid \\
EC2 & 0.846 & Valid \\
EC3 & 0.899 & Valid \\
IP1 & 0.738 & Valid \\
IP2 & 0.788 & Valid \\
IP3 & 0.896 & Valid \\
IP4 & 0.747 & Valid \\
IP5 & 0.781 & Valid \\
KN1 & 0.817 & Valid \\
KN2 & 0.829 & Valid \\
KN3 & 0.730 & Valid \\
KN4 & 0.818 & Valid \\
KN5 & 0.830 & \\
Sumber & &
\end{tabular}

Sumber: Hasil pengolahan SPSS (2020)

Reliabilitas diukur menggunakan pengujian statistik Cronbach's Alpha $(\alpha)$. Suatu variabel dikatakan reliabel apabila memberikan nilai Cronbach's Alpha >0.6. Jadi, semakin besar nilai $\alpha$ (alpha), maka semakin besar pula reliabilitasnya. Tabel 3 merupakan hasil pengujian validitas mengenai butir 
instrumen kenyamanan yang diberi kode $\mathrm{K}$, kualitas fungsional yang diberi kode $\mathrm{KF}$, digital banking service quality yang diberi kode $\mathrm{SQ}$, merek atau kepercayaan yang diberi kode $\mathrm{M}$, employee customer engagement yang diberi kode EC, inovasi perbankan digital yang diberi kode IP, dan kepuasan nasabah yang diberi kode KN. Untuk memermudah pembaca mengerti maksud Tabel 3 ini penulis memberi kode untuk setiap instrumen dari variabel penelitian ini.

Tabel 3. Hasil uji reliabilitas

\begin{tabular}{lll}
\hline Variabel/ indikator & Cronbach's alpha $(\alpha)$ & Status \\
\hline K & 0.769 & Reliabel \\
KF & 0.835 & Reliabel \\
SQ & 0.794 & Reliabel \\
M & 0.839 & Reliabel \\
EC & 0.850 & Reliabel \\
IP & 0.803 & Reliabel \\
KN & 0.805 & Reliabel \\
\hline
\end{tabular}

Sumber: Hasil pengolahan SPSS (2020)

\subsection{Hasil uji asumsi klasik}

\subsubsection{Uji normalitas}

Dari Gambar 1 dapat diketahui bahwa titik-titik data mengikuti dan mendekati garis diagonalnya, maka simpulannya adalah model regresi pada penelitian ini berdistribusi normal.

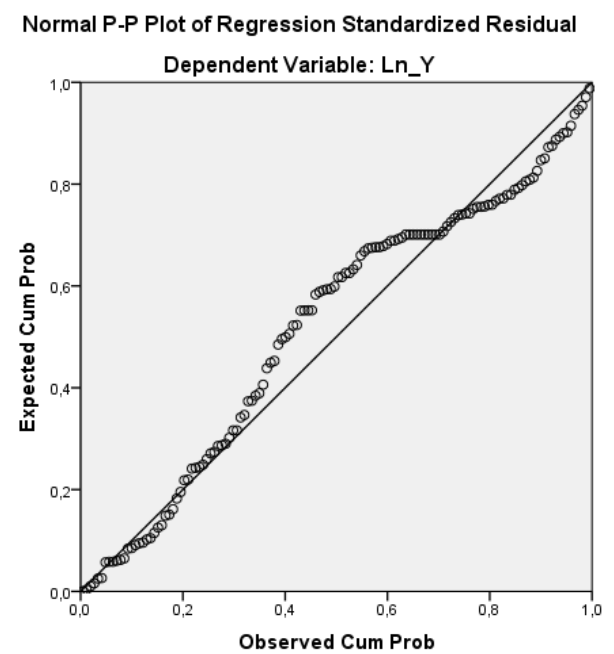

Gambar 1. Hasil uji normalitas

Sumber: Hasil pengolahan SPSS (2020)

\subsubsection{Uji heterokedastisitas}

Dari Gambar 2 dapat diketahui titik-titik menyebar dengan pola yang tidak jelas di atas dan di bawah angka 0 pada sumbu Y maka dapat disimpulkan bahwa tidak terjadi masalah heteroskedastisitas pada model regresi. 


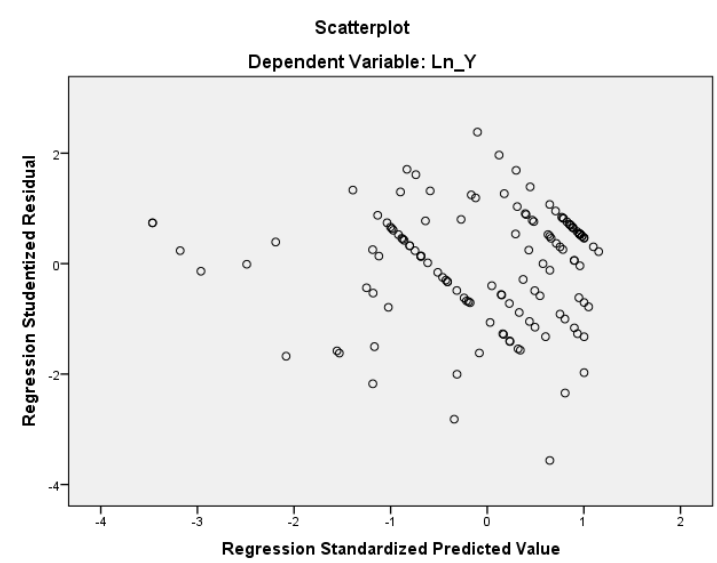

Gambar 2. Hasil uji heteroskedastisitas

Sumber: Hasil pengolahan SPSS (2020)

\subsubsection{Uji multikolinearitas}

Tabel 4 menyatakan bahwa hasil nilai Tolerance dari keenam variabel independen lebih dari 0.1 dan VIF kurang dari 10, maka simpulannya adalah model regresi berganda dalam penelitian ini tidak terjadi masalah multikolinearitas.

Tabel 4. Hasil uji multikolinearitas

\begin{tabular}{lll}
\hline Model & \multicolumn{2}{l}{ Collinearity statistics } \\
\cline { 2 - 3 } 1 Tolerance & VIF \\
& & \\
$\quad$ Kenyamanan & 0.490 & 2.040 \\
$\quad$ Kualitas fungsional & 0.329 & 3.041 \\
$\quad$ Digital banking service quality & 0.491 & 2.039 \\
$\quad$ Merek/ Kepercayaan & 0.280 & 3.577 \\
$\quad$ Employee customer engagement & 0.429 & 2.333 \\
$\quad$ Inovasi perbankan digital & 0.332 & 3.009 \\
a. Dependent Variable: Kepuasan nasabah & & \\
\hline
\end{tabular}

Sumber: Hasil pengolahan SPSS (2020)

\subsubsection{Uji autokorelasi}

Dari Tabel 5 dapat diketahui bahwa nilai dL dan dU Durbin Watson yaitu signifikasi 0.05. Nilai dL sebesar 1.6133 dan dU sebesar 1.8292. Dari hasil ini dinyatakan bahwa nilai Durbin Watson sebesar 1.986 yang terletak pada daerah $\mathrm{dU}<1.986<4-\mathrm{dU}$ atau $1.8292<1.986<2.1708$ sehingga simpulannya adalah model regresi ini tidak terjadi masalah autokorelasi.

Tabel 5. Hasil uji autokorelasi

\begin{tabular}{|c|c|c|c|c|c|}
\hline Model & $\mathrm{R}$ & R square & Adjusted $\mathrm{R}$ square & Std. error of the estimate & Durbin-Watson \\
\hline 1 & $.858^{\mathrm{a}}$ & .737 & .725 & .07223 & 1.986 \\
\hline \multicolumn{6}{|c|}{$\begin{array}{l}\text { a. Predictors: }(\text { Constant }), \mathrm{Ln} \_\mathrm{X} 6, \mathrm{Ln} \_\mathrm{X} 1, \mathrm{Ln} \_\mathrm{X} 3, \mathrm{Ln} \_\mathrm{X} 5, \mathrm{Ln} \_\mathrm{X} 2, \mathrm{Ln} \_\mathrm{X} 4 \\
\text { b. Dependent Variable: } \mathrm{Ln} \_\mathrm{Y}\end{array}$} \\
\hline
\end{tabular}

Sumber: Hasil pengolahan SPSS (2020) 


\subsection{Hasil uji hipotesis}

\subsubsection{Uji F (Anova)}

Tabel 6 menyatakan bahwa nilai signifikansi sebesar 0.000 memunyai nilai yang lebih kecil dari 0.05 , sehingga simpulannya adalah Ho ditolak. Artinya setidaknya ada salah satu variabel independen yang berpengaruh signifikan terhadap kinerja kepuasan nasabah perbankan dengan tingkat kepercayaan sebesar $95 \%$.

Tabel 6. Uji F (anova)

\begin{tabular}{llllll}
\hline ANOVA $^{\mathrm{a}}$ & & & & \\
Model & Sum of squares & $\mathrm{Df}$ & Mean square & $\mathrm{F}$ & Sig. \\
$1 \quad$ Regression & 1.885 & 6 & .314 & 60.195 & $.000^{\mathrm{b}}$ \\
$\quad$ Residual & .673 & 129 & .005 & & \\
$\quad$ Total & 2.558 & 135 & & & \\
a. Dependent Variable: $\mathrm{Ln} \_\mathrm{Y}$ & & & & \\
b. Predictors: (Constant), Ln_X6, Ln_X1, Ln_X3, Ln_X5, Ln_X2, Ln_X4 & & \\
\hline
\end{tabular}

Sumber: Hasil pengolahan SPSS (2020)

\subsubsection{Uji $t$}

Tabel 7 menunjukkan bahwa variabel kenyamanan dan digital banking service quality memiliki nilai signifikasi yang lebih besar dari 0.05. Maka hipotesis pertama dan ketiga dapat disimpulkan bahwa Ho tidak ditolak sehingga tidak terdapat pengaruh yang signifikan variabel kenyamanan dan digital banking service quality terhadap kinerja kepuasan nasabah perbankan dengan tingkat kepercayaan sebesar $95 \%$. Sedangkan variabel kualitas fungsional, employee customer engagement, dan inovasi perbankan digital memiliki nilai signifikasi yang lebih kecil dari 0.05. Maka hipotesis kedua, kelima, dan keenam dapat disimpulkan bahwa Ho ditolak sehingga terdapat pengaruh yang signifikan variabel kualitas fungsional, employee customer engagement, dan inovasi perbankan digital terhadap kinerja kepuasan nasabah perbankan dengan tingkat kepercayaan sebesar 95\%. Serta variabel merek/ kepercayaan memiliki nilai signifikansi yang lebih besar sedikit dari 0.05. Maka hipotesis keempat dapat disimpulkan bahwa Ho tidak ditolak sehingga tidak terdapat pengaruh variabel merek/ kepercayaan terhadap kinerja kepuasan nasabah perbankan dengan tingkat kepercayaan sebesar 95\%.

Tabel 7. Uji t

\begin{tabular}{cll}
\hline Model & & Sig. \\
\hline 1 & (Constant) & \\
& Kenyamanan & 0,289 \\
& Kualitas fungsional & 0,002 \\
& Digital banking service quality & 0,748 \\
& Merek/ Kepercayaan & 0,057 \\
& Employee customer engagement & 0,000 \\
& Inovasi perbankan digital & 0,000
\end{tabular}

Sumber: Hasil pengolahan SPSS (2020)

\subsubsection{Uji koefisien determinasi}

Dari Tabel 8, nilai $\mathrm{R}^{2}$ ialah sebesar 0.725 atau sama juga dengan $72.5 \%$. Angka tersebut dapat diartikan bahwa sebesar $72.5 \%$ variabel dependen yaitu kinerja kepuasan nasabah perbankan dapat dijelaskan oleh variabel independennya yaitu kenyamanan, kualitas fungsional, digital banking service quality, 
merek/ kepercayaan, employee customer engagement, dan inovasi perbankan digital. Sedangkan untuk sisanya yaitu $27.5 \%$ dapat diartikan oleh variabel-variabel lain di luar model regresi tersebut.

Tabel 8. Uji koefisien determinasi

\begin{tabular}{|c|c|c|c|c|}
\hline \multirow[b]{2}{*}{ Model } & \multicolumn{3}{|c|}{ Model Summary ${ }^{b}$} & \multirow[b]{2}{*}{ Durbin-Watson } \\
\hline & $\mathrm{R}$ & Adjusted R square & Std. error of the estimate & \\
\hline 1 & $.858^{\mathrm{a}}$ & .737 & .07223 & 1.986 \\
\hline \multicolumn{5}{|c|}{$\begin{array}{l}\text { a. Predictors: }(\text { Constant }), \mathrm{Ln} \_\mathrm{X} 6, \mathrm{Ln} \_\mathrm{X} 1, \mathrm{Ln} \_\mathrm{X} 3, \mathrm{Ln} \_\mathrm{X} 5, \mathrm{Ln} \_\mathrm{X} 2, \mathrm{Ln} \_\mathrm{X} 4 \\
\text { b. Dependent Variable: } \mathrm{Ln} \_\mathrm{Y}\end{array}$} \\
\hline
\end{tabular}

Sumber: Hasil pengolahan SPSS (2020)

\subsection{Pembahasan}

Berdasarkan hasil analisis di atas, variabel independen yang terdiri dari kenyamanan, kualitas fungsional, digital banking service quality, merek/ kepercayaan, employee customer engagement, dan inovasi perbankan digital berpengaruh signifikan terhadap kinerja kepuasan nasabah PT Bank Central Asia, Tbk. yang ditunjukkan oleh nilai sig F sebesar $0.000<0.05$.

Keberhasilan suatu perbankan bukan hanya terletak pada banyaknya nasabah yang diperoleh melainkan perbankan juga harus memertahankan agar nasabah tidak pindah ke bank lainnya. Seperti yang diketahui, pada era modern ini banyak layanan-layanan perbankan baru yang muncul seiring dengan perkembangan teknologi yang semakin maju, hal ini juga yang mendorong munculnya pendirian perusahaan baru yang berbasis FinTech sehingga tenjadi peningkatan tingkat persaingan antar bank untuk mencari cara memertahankan kepuasan nasabah tersebut.

Kenyamanan tidak memengaruhi kepuasan nasabah Bank BCA, padahal kenyamanan menjadi hal yang sangat penting karena menjadi modal awal agar nasabah dapat puas akan layanan yang diberikan oleh bank tersebut (Karim, 2017). Pernyataan tersebut diperkuat dengan hasil penelitian terdahulu yang menyatakan bahwa ada pengaruh yang signifikan antara kenyamanan terhadap kepuasan nasabah perbankan (Mbama \& Ezepue, 2018; Vebiana, 2018). Sedangkan hasil penelitian yang diteliti oleh penulis membuktikan bahwa kenyamanan nasabah tidak memiliki pengaruh signifikan terhadap kepuasan nasabah Bank BCA. Beberapa waktu lalu, terdapat perbincangan hangat di media sosial mengenai keluhan aplikasi BCA mobile yang mengalami gangguan. Nasabah yang menggunakan aplikasi $m$-banking dan $e$-banking sebagian besar tidak dapat melakukan transaksi melalui smartphone mereka (CNN Indonesia, 2019). Walaupun hal ini cepat ditanggapi oleh pihak Bank BCA dengan mengklarifikasi terjadi gangguan pada aplikasi mereka melalui twitter @ HaloBCA, namun para nasabah sadar bahwa kejadian serupa dapat terjadi kembali sewaktu-waktu.

Kualitas fungsional berpengaruh signifikan terhadap kinerja kepuasan nasabah perbankan. Hasil dalam penelitian ini tentunya sejalan dengan penelitian terdahulu yang menyatakan bahwa ada pengaruh yang signifikan antara kualitas fungsional terhadap kinerja kepuasan nasabah perbankan (Mbama \& Ezepue, 2018; Vebiana, 2018). Dengan kata lain bahwa kualitas fungsional menjadi salah satu cara untuk memertahankan kepuasan para nasabah Bank BCA.

Digital banking service quality tidak berpengaruh signifikan terhadap kepuasan nasabah Bank BCA, padahal semakin baik digital banking service quality yang diberikan bank, maka akan dapat meningkatkan kepuasan pada nasabahnya (Anggraeni \& Yasa, 2012). Pernyataan tersebut diperkuat dengan hasil penelitian terdahulu yang menyatakan bahwa ada pengaruh yang signifikan antara digital banking service quality terhadap kepuasan nasabah perbankan (Mbama \& Ezepue, 2018; Vebiana, 2018). Namun hasil penelitian berbeda yang diteliti oleh penulis ini membuktikan sekaligus menunjukkan bahwa terdapat peranan penting dari adanya interaksi antara nasabah dengan teller atau customer service secara langsung, sehingga peran kantor cabang belum dapat tergantikan dengan layanan secara digital. Hal ini yang menyebabkan digital banking service quality di dalam memengaruhi kepuasan nasabah menjadi kurang terasa atau kurang signifikan.

Merek/ kepercayaan tidak berpengaruh signifikan terhadap kinerja kepuasan nasabah perbankan, padahal keyakinan atau kepercayaan akan menciptakan sebuah hubungan yang dekat antar pihak yang 
terlibat pertukaran (Suhardi, 2006). Dan juga konsumen yang memiliki citra yang positif terhadap suatu merek akan lebih memungkinkan untuk melakukan pembelian ulang (Setiadi, 2003). Hal ini juga sama halnya dengan perbankan. Apabila nasabah terus merasa puas dan positif akan layanan yang diberikan bank tersebut maka merek/ kepercayaan lah yang menjadi kunci bank untuk meningkatkan serta memertahankan nasabah tersebut. Pernyataan tersebut diperkuat dengan hasil penelitian yang menyatakan bahwa ada pengaruh yang signifikan antara merek/ kepercayaan terhadap kepuasan nasabah perbankan (Mbama \& Ezepue, 2018; Vebiana, 2018). Hasil penelitian yang diteliti oleh penulis ini membuktikan bahwa merek/ kepercayaan Bank BCA tidak memengaruhi kepuasan nasabahnya. Kendati demikian, merek/ kepercayaan Bank BCA sudah kuat di benak para nasabahnya sehingga tidak memengaruhi kepuasaan dari para nasabahnya.

Employee customer engagement berpengaruh signifikan terhadap kinerja kepuasan nasabah perbankan. Hasil dalam penelitian ini tentunya sejalan dengan penelitian terdahulu yang menyatakan bahwa ada pengaruh yang signifikan antara employee customer engagement terhadap kepuasan nasabah perbankan (Mbama \& Ezepue, 2018; Vebiana, 2018). Hasil ini menunjukkan para nasabah Bank BCA sudah puas dengan pelayanan yang diberikan para karyawan Bank BCA.

Inovasi perbankan digital berpengaruh signifikan terhadap kinerja kepuasan nasabah perbankan. Hasil dalam penelitian ini sejalan dengan penelitian terdahulu yang menyatakan bahwa ada pengaruh yang signifikan antara inovasi perbankan digital terhadap kinerja kepuasan nasabah perbankan (Mbama \& Ezepue, 2018; Vebiana, 2018). Dengan kata lain bahwa para nasabah sudah puas dengan inovasiinovasi perbankan digital yang sudah dilakukan oleh Bank BCA. Bank BCA juga telah menyediakan semua fitur oneclick untuk memberikan kemudahan transaksi bagi para nasabahnya.

\section{SIMPULAN DAN SARAN}

Pada penelitian ini, kenyamanan, digital banking service quality, dan merek/ kepercayaan tidak berpengaruh terhadap kinerja kepuasan nasabah perbankan. Hasil ini tidak sejalan dengan penelitian yang diteliti oleh Mbama \& Ezepue (2018). Sedangkan kualitas fungsional, employee customer engagement, dan inovasi perbankan digital berpengaruh terhadap kinerja kepuasan nasabah perbankan. Hasil ini sejalan dengan penelitian yang diteliti oleh Mbama \& Ezepue (2018).

Berdasarkan hasil dan pembahasan serta kesimpulan yang telah dipaparkan maka rekomendasi atau saran yang dapat disampaikan adalah bagi Bank BCA untuk dapat memertahankan dan meningkatkan layanan perbankan digital sehingga dapat dimanfaatkan secara optimal dalam meningkatkan kepuasan nasabah. Bagi peneliti selanjutnya, agar dapat melakukan penelitian terhadap variabel-variabel lain yang dapat memengaruhi kepuasan nasabah selain yang diteliti dalam penelitian ini. Peneliti percaya bahwa masih ada banyak variabel lainnya yang memiliki pengaruh terhadap kepuasan yang tidak diteliti pada penelitian ini. Bagi peneliti selanjutnya juga dapat melakukan penelitian terhadap model dalam penelitian ini ke dalam industri yang lain di Indonesia, selain dari industri perbankan.

\section{REFERENSI}

Anggraeni, N.M.S. \& Yasa, N.N. K. (2012). E-service quality terhadap kepuasan dan loyalitas pelanggan dalam penggunaan internet banking. Jurnal Keuangan dan Perbankan. 16, 293-306

CNN Indonesia. (2019, 3 Desember). Warganet keluhkan aplikasi BCA mobile bermasalah. Diperoleh dari https://www.cnnindonesia.com/teknologi/20191203002951-192-453551/warganet-keluhkanaplikasi-bca-mobile-bermasalah

Hastuti, R.K. (2019, 11 November). Bos BCA: Kami sudah digital bank. Diperoleh dari https://www.cnbcindonesia.com/tech/20191111181222-37-114430/bos-bca-kami-sudah-digitalbank

Karim, K. (2017, Maret). Kajian mengenai kepuasan nasabah bank syariah di kota Makassar. Diperoleh dari 
https://www.researchgate.net/publication/335250814_KAJIAN_MENGENAI_KEPUASAN_NAS ABAH_BANK_SYARIAH

Kholis, N. (2018). Perbankan dalam era baru digital. Economicus. 9(1)

Koran SINDO. (2019, 24 Februari). Ikuti era digital, BCA incar pasar milenial. Diperoleh dari https://economy.okezone.com/read/2019/02/24/320/2022085/ikuti-era-digital-bca-incar-pasarmilenial

Mbama, C.I. \& Ezepue, P.O. (2018). Digital banking, customer experience and bank financial performance: UK customers' perceptions. Emerald, 36(2), 230-255

Setiadi, N.J. (2003). Perilaku konsumen: Konsep dan implikasi untuk strategi dan penelitian pemasaran. Jakarta: Prenada Media Jakarta

Suhardi, G. (2006). Faktor-faktor yang mempengaruhi kepercayaan dan loyalitas nasabah perbankan di Surabaya. Jurnal Kinerja. 10(1)

Sukmana, Y. (2019, 16 Juli). Fenomena bank sibuk tutup kantor cabangnya, ini kata OJK. Diperoleh dari https://www.google.com/amp/s/amp.kompas.com/money/read/2019/07/16/193017926/fenomenabank-sibuk-tutup-kantor-cabangnya-ini-kata-ojk

Tabachnik, B.G. \& Fidel, L.S. (2013). Using multivariate stastics, Sixth Ed. Boston: Pearson Education, Inc. Diperoleh dari https://www.pearson.com/us/higher-education/program/Tabachnick-UsingMultivariate-Statistics-7th-Edition/PGM2458367.html

Vebiana, V. (2018). Perbankan digital, pengalaman pelanggan, dan kinerja keuangan bank syariah. Proceedings of the 9th Industrial Research Workshop and National Seminar, 9, 747-751 
Jurnal Manajemen Maranatha — Vol. 19 Nomor 2, Mei 2020 